\title{
Estudo preliminar da utilização de otólitos de Cynoscion acoupa sobre o processo de neoformação óssea em ratos
}

\author{
Preliminary study of using otoliths of Cynoscion acoupa upon the process of bone regeneration in rats
}

Daisy Pereira Valido'; Talita Santos Bastos²; Ricardo Luiz Cavalcanti de Albuquerque-Júnior3; Maria Amália Gonzaga Ribeiro4; André Luiz Santos Barreto ${ }^{5}$; Lauro Xavier-Filho ${ }^{6}$; Sheyla Alves Rodrigues'; Ana Maria Guedes de Brito ${ }^{8}$

unitermos
Otólitos
Neoformação óssea
Biominerais

\section{resumo}

Introdução: Otólitos são concrescências calcárias presentes no ouvido interno de peixes. Por serem ricos em minerais considerados essenciais ao processo de mineralização óssea sobre uma matriz proteica (otolina), sugere-se que otólitos poderiam funcionar como biominerais. Objetivo: Avaliar a capacidade de regeneração de defeitos ósseos tratados com preparado gelatinoso estéril de otólitos. Material e método: $\mathrm{O}$ experimento foi realizado com 20 ratos Wistar, distribuídos aleatoriamente em dois grupos, nos quais se realizou defeito ósseo na tíbia, sendo o grupo 1 (G1) experimental, cujas lojas ósseas foram preenchidas com preparado de otólitos, e o grupo 2 (G2) controle, cujas lojas ósseas não receberam tratamento adicional. Os animais foram sacrificados 14 dias após os procedimentos cirúrgicos; as tíbias foram removidas, fixadas em formalina a $10 \%$, descalcificadas em ácido nítrico a $5 \%$ e processadas histologicamente. Antes dos sacrifícios, foram coletadas amostras sanguíneas para avaliação das dosagens séricas de cálcio ( $\mathrm{Ca}$ ) e fosfatase alcalina (Alkp). Resultados: As secções histológicas revelaram que o trabeculado ósseo neoformado mostrou-se mais denso e com atividade osteorreabsortiva periosteal menos conspícua no grupo experimental. Entretanto, não demonstraram diferenças estatisticamente significativas na área de neoformação óssea entre $\mathrm{G} 1\left(1,9 \pm 0,3 \mathrm{~mm}^{2}\right)$ e $\mathrm{G} 2\left(1,5 \pm 0,4 \mathrm{~mm}^{2}\right)(p=0,0617)$. Os parâmetros bioquímicos (Ca e Alkp) apresentaram-se dentro dos limites de normalidade. Discussão/conclusão: Os dados sugerem que os otólitos podem desempenhar papel adjuvante na dinâmica da regeneração óssea.

\section{abstract}

Introduction: Otoliths are calcareous concrescences present in the inner ear of fishes. Since they are rich in minerals considered essential to the bone mineralization process on a protein matrix (otolin), it has been suggested that otoliths may work as biominerals. Objective: The objective in this study was to analyze the regeneration capacity of bone defects treated with sterile gelatinous otolith preparation. Material and method: The experiment was performed with 20 Wistar rats randomized into two groups, in which a bone defect was inflicted in the tibia. In group 1 (experimental), bone cavities were filled with otoliths. In group 2 (control), bone cavities did not receive any additional treatment. The animals were sacrificed 14 days after surgical procedures. The tibias were removed, fixed in formalin at 10\%, decalcified in nitric acid at $5 \%$ and histologically processed. Before sacrifice, blood samples were collected to evaluate serum dosage of calcium ( $\left.\mathrm{Ca}^{2+}\right)$ and alkaline phosphatase (Alkp). Results: Histological sections revealed that the newly formed trabecular bone was denser and the periosteal reabsorptive activity was less conspicuous in the experimental group. However, there was no statistically significant difference in the area of bone formation between $G 1$ $\left(1.9 \pm 0.3 \mathrm{~mm}^{2}\right)$ and $\mathrm{G} 2\left(1.5 \pm 0.4 \mathrm{~mm}^{2}\right)(\mathrm{p}=0.0617)$. Biochemical $\left(\mathrm{Ca}^{2+}\right.$ and Alkp) parameters were within normal range. Discussion/conclusion: These data suggest that otoliths may be an adjuvant to the dynamics of bone regeneration.

\footnotetext{
1. Odontóloga; mestranda em Saúde e Ambiente pela Universidade Tiradentes (UNIT).

2. Acadêmica de Biomedicina da UNIT; bolsista do Programa de Bolsas de Iniciação Científica (PROBIC).

3. Odontólogo; doutor em Patologia Oral; pesquisador do Laboratório de Morfologia e Biologia Estrutural do Instituto de Tecnologia e Pesquisa (LMBE-ITP) e professor de pós-graduação em Saúde e Ambiente da UNIT.

4. Odontóloga; doutora em Laser em Odontologia; pesquisadora do LMBE-ITP e professora da UNIT.

5. Odontólogo; mestre em Saúde e Ambiente; pesquisador colaborador do LMBE-ITP da UNIT.

6. Biólogo; doutor em Ciências Biológicas; pesquisador do Laboratório de Produtos Naturais e Biotecnologia do ITP e professor de pós-graduação em Saúde e Ambiente da UNIT.

7. Bióloga e biomédica; doutoranda em Biotecnologia; pesquisadora do Laboratório de Produtos Naturais e Biotecnologia do ITP e professora da UNIT.

8. Farmacêutica; mestra em Saúde e Ambiente; pesquisadora do Laboratório de Produtos Naturais e Biotecnologia do ITP e professora da UNIT.
} 


\section{Introdução}

O tecido ósseo é frequentemente acometido por defeitos provocados por traumatismos, patologias de origens e comportamentos variados, infecções e deformidades congênitas ${ }^{(12)}$. O reparo de tais defeitos ósseos continua sendo um desafio, nos quais métodos tradicionais de tratamento utilizam o enxerto ósseo autógeno, especialmente por atuar na osteogênese e facilitar a incorporação em relação aos enxertos homógenos e xenógenos. Ressalta-se, contudo, que a aquisição de enxerto ósseo autógeno agrega alguns riscos ao paciente, a exemplo de incisão cirúrgica adicional, aumento da morbidade pós-operatória, debilitação do local doador e disponibilidade de quantidade insatisfatória de material para enxerto(7). Em vista dessas dificuldades, grande variedade de materiais alternativos para preenchimento de defeitos ósseos (biomateriais) tem sido desenvolvida ${ }^{(6,11)}$.

Os biomateriais caracterizam-se por sua biocompatibilidade e atoxicidade, além de não apresentarem carcinogenicidade e de exibirem resistência mecânica, elasticidade e estabilidades química e biológica ${ }^{(8)}$. Biomateriais inorgânicos são, por sua vez, compostos alternativos ao uso de enxertos ósseos autógenos por serem produzidos com propriedades potencialmente semelhantes às do tecido receptor e, quando usados em defeitos ósseos de grande amplitude, constituem elementos capazes de promover ou auxiliar a neoformação óssea por mecanismos de osteoindução e/ou osteocondução(20). Ressalta-se, ainda, a presença de uma matriz orgânica que acelera a neoformação óssea por facilitar a incorporação de minerais por difusão passiva ${ }^{(2)}$.

Entre os diversos biomateriais com provável atividade sobre a neoformação óssea, merece destaque o grupo dos biominerais, que se caracterizam por sua rigidez, consistindo basicamente de compostos inorgânicos. Entre suas funções, pode-se citar manutenção da estrutura corporal, proteção, estocagem de minerais, entre outras ${ }^{(15,18)}$. Tais biominerais consistem em uma fase predominantemente mineral incorporada a uma matriz orgânica, representada por rede complexa de glicoproteínas, proteoglicanas, proteínas colagênicas e não colagênicas ${ }^{(14)}$. A superfície das partículas dos biomateriais atua como uma matriz sobre a qual a reparação óssea se desenvolve ${ }^{(5)}$.

Os otólitos são estruturas ósseas presentes no ouvido interno dos peixes ósseos e constituem parte de um sistema que atua como sensor de profundidade e equilíbrio, assim como detector de vibrações sonoras ${ }^{(1)}$. Estudos vêm demonstrando que otólitos são ricos em carbonato de cálcio, elementos metálicos ( $\mathrm{Sr}, \mathrm{Ba}, \mathrm{Mg}, \mathrm{Cd}, \mathrm{Co}, \mathrm{Cu}, \mathrm{Zn}, \mathrm{Na}$, K etc.) e não metálicos (Si, $\mathrm{P}, \mathrm{S}, \mathrm{B}$ etc.) $)^{(3)}$ e uma proteína colagênica de alto peso molecular denominada otolina ${ }^{(1,2,6,16,22)}$.

Admite-se, pois, que otólitos poderiam representar um excelente exemplo de biomineral, uma vez que apresentam uma porção inorgânica rica em elementos essenciais ao processo de mineralização óssea, bem como uma parte proteica (otolina), que poderia funcionar como matriz orgânica.

\section{Objetivo}

Verificar o processo regenerativo de defeitos ósseos artificialmente induzidos frente ao preenchimento com preparado gelatinoso estéril de otólitos, com o intuito de avaliar se há a influência de biominerais (nesse caso, otólitos de pescada amarela) como fator adjuvante no processo de neoformação óssea.

\section{Material e método}

\section{Obtenção do preparado de otólitos}

Cerca de $100 \mathrm{~g}$ de otólitos de pescada amarela foram triturados em almofariz até ser obtido um pó de granulação delicada e coloração esbranquiçada. O composto final foi diluído em gelatina incolor, acondicionado em placas de Petri e esterilizado em raios gama/cobalto 60 .

\section{Experimentação em animais}

A experimentação animal foi submetida ao Comitê de Ética em Pesquisa da Universidade Tiradentes (Aracaju-SE), sendo a mesma aprovada no dia 10/02/2006, sob o protocolo 171205, de acordo com os princípios éticos para o uso de animais de laboratório, dispostos na lei 1.153-b de 1995.

Foram utilizados 20 (vinte) ratos machos de linhagem Wistar, com peso médio de $300 \mathrm{~g}( \pm 50 \mathrm{~g})$, distribuídos em dois grupos com 10 (dez) animais: grupo 1 (experimental) e grupo 2 (controle). Para confecção do defeito ósseo, os animais foram anestesiados com solução 1:1 de xilazina e quetamina na dosagem de $0,1 \mathrm{ml} \times 100 \mathrm{~g}^{-1}$ de peso por via intramuscular (IM). Após tricotomia, foi realizada incisão longitudinal de $20 \mathrm{~mm}$ em face lateral da coxa esquerda, divulsão romba da musculatura com exposição da diáfise do fêmur e confecção do defeito na superfície óssea com perfurador elétrico (Singer, mod. 900, 110-120 V, 60 Hz, 20 A e $2.000 \mathrm{rpm}$ ) e broca de aço de uso odontológico $\mathrm{n}^{\circ} .6$, adaptada a contra-ângulo de $22 \mathrm{~mm}$ de comprimento, na porção 
proximal do fêmur, perpendicularmente ao plano ósseo sagital. Foram perfuradas as corticais mediais, na região diafisária, conforme preconizado por Ribeiro et al.(19)

Posteriormente, os defeitos dos animais do grupo 1 foram preenchidos com o preparado estéril, composto por otólitos de pescada amarela, triturados e diluídos em gelatina. Os animais do grupo 2 não receberam qualquer tratamento adicional à confecção dos defeitos. A aproximação muscular foi efetuada com pontos simples de categute 3-0 e sutura contínua da incisão cutânea com fio monofilamentado de poliamida 4-0. Os animais foram mantidos em gaiolas, sem nenhum recurso de imobilização externa dos membros operados, com ração e água ad libitum.

Foram sacrificados no décimo quarto dia após a cirurgia, com injeção intramuscular de zoletil $(0,8 \mathrm{ml} / \mathrm{kg})$ e de tiopental sódico $(0,43 \mathrm{ml} / \mathrm{kg})$ após 10 minutos, e de cloreto de potássio $(5 \mathrm{ml} / \mathrm{kg})$ após 5 minutos. Em seguida, o fêmur foi removido para realização de análise morfológica.

\section{Hemograma, dosagem sérica de cálcio e fosfatase alcalina}

Foram coletados $600 \mathrm{ml}$ de sangue, obtidos por punção da veia mesentérica. Inicialmente realizou-se o hemograma completo e em seguida foram determinados os níveis de fosfatase alcalina sérica, por meio de kit diagnóstico. As dosagens séricas de cálcio e de enzima fosfatase alcalina por método colorimétrico foram realizadas com o soro. Essas dosagens serviram como marcadores bioquímicos para evidenciar o direcionamento do cálcio no processo de osteoregeneração.

\section{Análise morfológica}

As tíbias foram removidas cirurgicamente, fixadas em solução de formol tamponada (tampão fosfato, pH 7,4) por 24 horas e, subsequentemente, foram descalcificadas em solução de ácido nítrico a 5\%. Após o processo de descalcificação, as tíbias foram hemisseccionadas em seu longo eixo e submetidas ao processo de rotina para inclusão em parafina. Secções histológicas de $5 \mathrm{~mm}$ de espessura do material emblocado foram obtidas e coradas em hematoxilina/eosina (HE) para análise morfológica e morfométrica do tecido mineralizado neoformado na área da osteotomia.

Neste estudo foram confeccionadas cinco secções histológicas seriadas de $5 \mu \mathrm{m}$ de espessura, separadas entre si por distância de $10 \mu \mathrm{m}$; em cada lâmina foram fotomicrografados quatro campos histológicos (ampliação de 400x), uma vez que na ampliação de 40x e 100x não foi possível observar de forma nítida as alterações decorrentes do processo em estudo, selecionados de modo a perfazer toda a área de neoformação óssea. As lâminas foram observadas e analisadas por um único pesquisador. As imagens fotomicrografadas foram digitalizadas por meio de software de captura de imagens Olympus $2000^{\circledR}$, projetadas em monitor Samsung ${ }^{\circledR}$ de $14^{\prime \prime}$ e submetidas ao processamento em software específico para morfologia (Image Too ${ }^{\circledR}$ ), para determinação do valor total da área ocupada pelo tecido ósseo depositado na região correspondente à ferida óssea artificialmente induzida (Figura 1). Para tanto, o programa foi calibrado para que os valores fossem obtidos em micrômetros quadrados $\left(\mu \mathrm{m}^{2}\right)$.

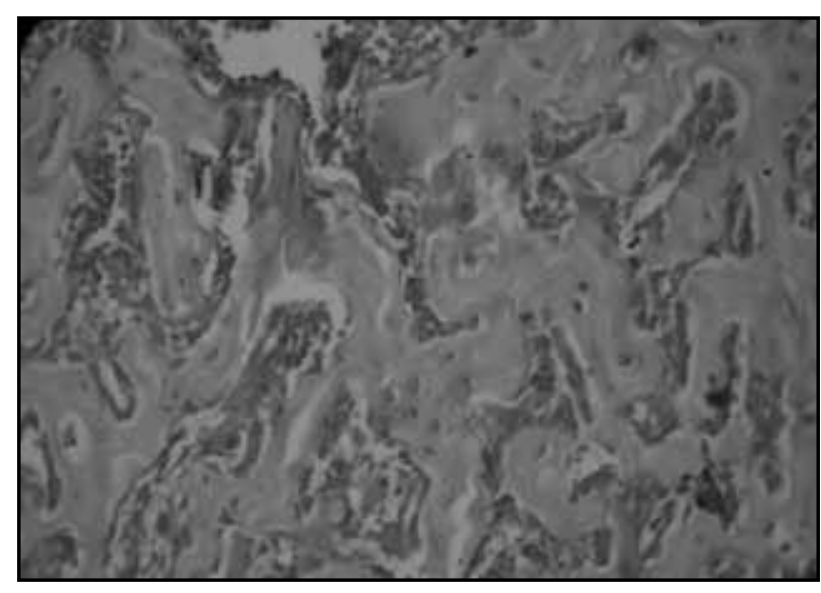

Figura 1 - Tela aberta do software Image Too ${ }^{\circledR}$ durante procedimento de análise morfométrica da área de neoformação óssea nos grupos estudados

\section{Análise estatística}

As médias dos valores da dosagem de fosfatase alcalina sérica e as médias da área de neoformação óssea foram comparadas entre os grupos experimental (grupo 1) e controle (grupo 2) por meio do teste t de Student. Os valores obtidos no hemograma foram comparados entre os grupos por intermédio do teste Qui-quadrado. Foram consideradas diferenças significativas quando $p<0,05$.

\section{Resultados}

Em todos os casos foi observada a neoformação de trabéculas ósseas, a maioria com aparência irregular, aspecto intensamente entrelaçado e espessura delgada. As trabéculas estendiam-se, de forma geral, de um lado a outro do defeito ósseo artificialmente induzido, exibindo atividade osteoblástica. Os espaços medulares exibiam escassa infiltração inflamatória e apresentavam-se com tamanho reduzido, particularmente no grupo experimental 
(Figuras 2A e 2B). O periósteo, por sua vez, demonstrou grau moderado de fibrose em ambos os grupos. No grupo experimental observou-se que a superfície do tecido ósseo apresentou maior regularidade e maior atividade osteoblástica em relação ao grupo controle, além de demonstrar áreas de atividades osteorreabsortiva mais evidentes (Figuras 2C e 2D).

A área média de neoformação óssea nos animais do grupo experimental foi de $1.906 .858,5 \mu^{2}( \pm 397.647,9)$ e de $1557682,1 \mu \mathrm{m}^{2}( \pm 425.608,2)$ no grupo controle (Figura 3). Apesar da tendência a uma maior área de neoformação óssea no grupo experimental, não foi observada diferença estatisticamente significativa $(p=0,0617)$.

A análise dos parâmetros bioquímicos demonstrou que a média da dosagem de cálcio foi de $9,05( \pm 0,47) \mathrm{mg} / \mathrm{dl}$ para o grupo experimental e de $8,79( \pm 0,33) \mathrm{mg} / \mathrm{dl}$ para o controle. Não houve diferença estatisticamente significativa

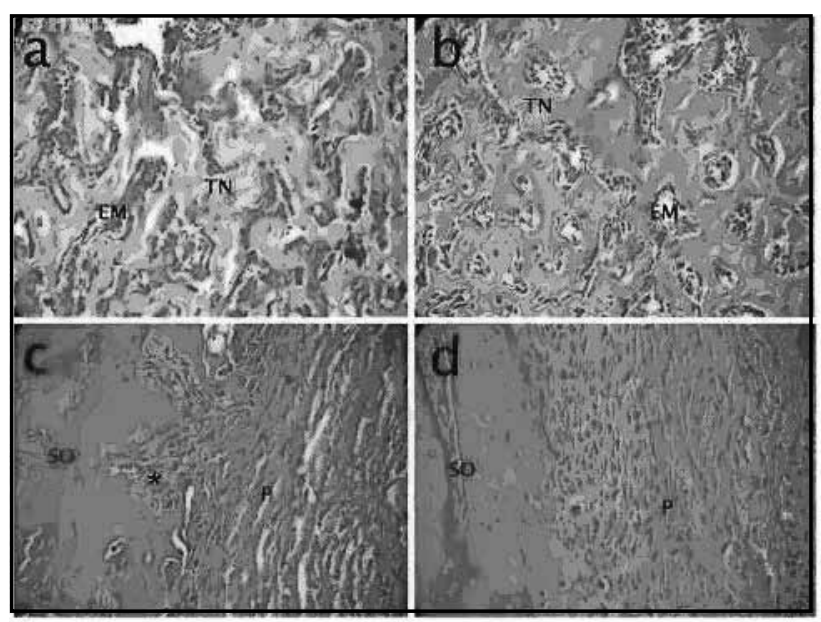

Figura 2 - Área osteotomizada exibindo trabéculas ósseas irregulares, delgadas e entrelaçadas (TN) e espaços medulares estreitados (EM) no grupo controle $(A)$ e no grupo experimental (B); observar tendência a maior estreitamento dos últimos em relação aos primeiros. 0 periósteo $(P)$ exibe fibrose em ambos os grupos, mas a superfície óssea (SO) demonstra maior irregularidade no grupo controle (C), inclusive com áreas de expressiva reabsorção óssea (*), em comparação ao grupo experimental (D) $(H E, 100 x)$

$H E$ : hematoxilina e eosina.

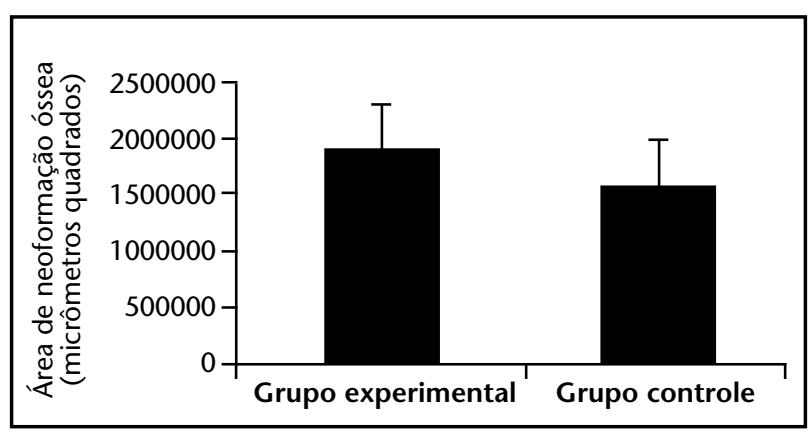

Figura 3 - Análise morfométrica da área de neoformação óssea na região osteotomizada $\left(\mu m^{2}\right)$ nos grupos experimental e controle

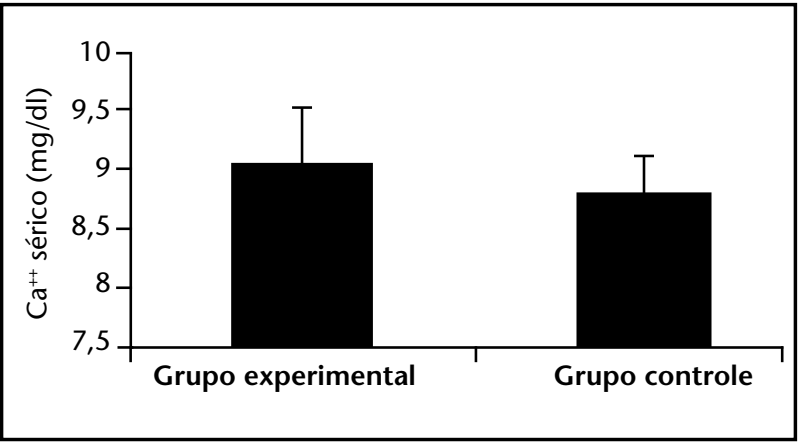

Figura 4 - Dosagens séricas de cálcio nos grupos experimental e controle

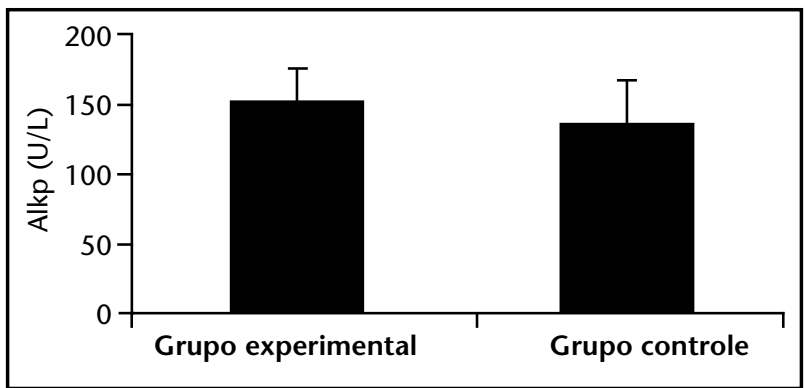

Figura 5 - Dosagens séricas de Alkp nos grupos experimental e controle Alkp: fosfatase alcalilna.

entre os grupos $(p=0,08)$. Além disso, os valores se mantiveram dentro da faixa de normalidade $(8-13 \mathrm{mg} / \mathrm{dl})$.

Já a análise dos níveis séricos de fosfatase alcalina demonstrou valores bastante elevados em ambos os grupos (152,3 $\pm 23,68 \mathrm{U} / \mathrm{L}$ no grupo experimental e $136,5 \pm 29,51 \mathrm{U} / \mathrm{L}$ no grupo controle), quando comparados ao parâmetro sérico normal ou basal (16-50 U/L). No entanto, não houve diferença estatisticamente significativa entre os grupos $(p=0,12)$.

A análise dos parâmetros hematológicos referentes à série branca revelou poucas alterações no grupo dos leucócitos mononucleares, representada por monocitose moderada em ambos os grupos. Granulócitos e linfócitos não exibiram variações importantes, apesar de os últimos se apresentarem no limite da faixa de normalidade (Tabela 1). Observou-se diferença estatisticamente significativa entre os grupos para o valor sérico relativo de monócitos $(p=0,001)$ e neutrófilos $(p=0,001)$, mas não para linfócitos $(p=0,336)$. Por outro lado, foram observadas diferenças estatisticamente significativas entre os dois grupos quando foram comparados os parâmetros hematológicos da série vermelha, que se mostraram mais elevados no grupo experimental, excetuando a contagem de plaquetas (PLT), na qual ocorreu o fenômeno inverso $(p<0,05)$ (Tabela 2). No entanto, os parâmetros se encontravam dentro do limite de normalidade, exceto o volume corpuscular médio (VCM), que estava diminuído. 
Tabela 1 Distribuição dos valores hematológicos da série leucocitária nos animais dos grupos controle e experimental

\begin{tabular}{|c|c|c|c|c|c|c|}
\hline \multirow{2}{*}{ Animais } & \multicolumn{2}{|c|}{ Linfócitos (\%) } & \multicolumn{2}{|c|}{ Monócitos (\%) } & \multicolumn{2}{|c|}{ Granulócitos (\%) } \\
\hline & GC & GE & GC & GE & GC & GE \\
\hline 1 & 58,4 & 56,9 & 25,2 & 12,2 & 16,4 & 30,9 \\
\hline 2 & 69,1 & 62,5 & 12,1 & 8,5 & 18,8 & 29 \\
\hline 3 & 66,1 & 67,7 & 16,9 & 8,3 & 17 & 24 \\
\hline 4 & 64 & 52,3 & 16,8 & 12,6 & 19,2 & 35,1 \\
\hline 5 & 64,2 & 65,4 & 14,6 & 9 & 21,2 & 25,1 \\
\hline 6 & 61,5 & 50,5 & 17,2 & 9,8 & 21,3 & 39,7 \\
\hline 7 & 72,9 & 69,3 & 13,6 & 8,9 & 13,5 & 21,8 \\
\hline 8 & 61,5 & 69,5 & 19,1 & 10,1 & 19,4 & 20,4 \\
\hline 9 & - & 61,9 & - & 9,6 & - & 28,5 \\
\hline 10 & - & - & - & - & - & - \\
\hline Média & $64,7 \pm 4,6$ & $61,7 \pm 7,1$ & $16,9 \pm 4,1$ & $9,8 \pm 1,543$ & $18,3 \pm 2,6$ & $28,2 \pm 6,2$ \\
\hline Valor de $p$ & \multicolumn{2}{|c|}{0,336} & \multicolumn{2}{|c|}{0,001} & \multicolumn{2}{|c|}{0,001} \\
\hline Referência & \multicolumn{2}{|c|}{60 a 80} & \multicolumn{2}{|c|}{0 a 5} & \multicolumn{2}{|c|}{10 a 30} \\
\hline
\end{tabular}

Tabela 2 Distribuição dos valores hematológicos relativos da série eritrocítica nos animais dos grupos controle e experimental

\begin{tabular}{|c|c|c|c|c|c|c|c|c|c|c|}
\hline \multirow{2}{*}{ Animais } & \multicolumn{2}{|c|}{$\mathrm{RBC}\left(10^{6} / \mathrm{mm}^{3}\right)$} & \multicolumn{2}{|c|}{$\begin{array}{l}H G B \\
(g / d l)\end{array}$} & \multicolumn{2}{|c|}{$\begin{array}{l}\text { HCT } \\
(L \%)\end{array}$} & \multicolumn{2}{|c|}{$\begin{array}{c}\text { VCM } \\
\left(\mathrm{L} \mu \mathrm{m}^{3}\right)\end{array}$} & \multicolumn{2}{|c|}{ PLT $\left(10^{3} / \mathrm{mm}^{3}\right)$} \\
\hline & $\begin{array}{l}\text { Grupo } \\
\text { controle }\end{array}$ & $\begin{array}{c}\text { Grupo } \\
\text { experimental }\end{array}$ & $\begin{array}{l}\text { Grupo } \\
\text { controle }\end{array}$ & $\begin{array}{c}\text { Grupo } \\
\text { experimental }\end{array}$ & $\begin{array}{l}\text { Grupo } \\
\text { controle }\end{array}$ & $\begin{array}{c}\text { Grupo } \\
\text { experimental }\end{array}$ & $\begin{array}{l}\text { Grupo } \\
\text { controle }\end{array}$ & $\begin{array}{c}\text { Grupo } \\
\text { experimental }\end{array}$ & $\begin{array}{l}\text { Grupo } \\
\text { controle }\end{array}$ & $\begin{array}{c}\text { Grupo } \\
\text { experimental }\end{array}$ \\
\hline R1 & 6,8 & 5,98 & 13,4 & 14,4 & 31,7 & 39,9 & 49 & 53 & 801 & 415 \\
\hline $\mathrm{R} 2$ & 5,88 & 7,44 & 12,9 & 13,2 & 32,2 & 37,4 & 50 & 51 & 755 & 772 \\
\hline R3 & 6,03 & 7,45 & 12,7 & 14,2 & 30,2 & 37,8 & 51 & 52 & 728 & 498 \\
\hline R4 & 5,39 & 7,38 & 12,7 & 14,6 & 31,1 & 36,6 & 50 & 54 & 714 & 475 \\
\hline R5 & 6,19 & 7,35 & 13,1 & 13,5 & 29,1 & 39,5 & 51 & 51 & 646 & 595 \\
\hline R6 & 6,04 & 7,42 & 13,1 & 14,4 & 31,7 & 37,7 & 48 & 53 & 652 & 415 \\
\hline R7 & 5,88 & 6,89 & 13,9 & 13,2 & 32,2 & 40,6 & 51 & 51 & 615 & 772 \\
\hline R8 & 6,03 & 7,1 & 13,7 & 14,2 & 30,2 & 41 & 52 & 52 & 532 & 498 \\
\hline R9 & 5,39 & 6,07 & 15,1 & 14,6 & 31,1 & 46 & 51 & 54 & 752 & 475 \\
\hline R10 & 6,19 & 6,8 & 13 & 13,5 & 29,1 & 39,4 & 50 & 51 & 645 & 595 \\
\hline Média & $\begin{array}{l}59,82 \\
\pm 0,4\end{array}$ & $\begin{array}{r}69,88 \\
\pm 0,55\end{array}$ & $\begin{array}{r}13,36 \\
\pm 0,72\end{array}$ & $\begin{array}{r}13,98 \\
\pm 0,56\end{array}$ & $\begin{array}{r}30,86 \\
\pm 1,16\end{array}$ & $\begin{array}{r}39,59 \\
\pm 2,68\end{array}$ & $\begin{array}{c}50,3 \\
\pm 1,159\end{array}$ & $\begin{array}{c}52,2 \\
\pm 1,22\end{array}$ & $\begin{array}{c}684 \\
\pm 80,3\end{array}$ & $\begin{array}{c}551 \\
\pm 131,53\end{array}$ \\
\hline \multirow{2}{*}{ Valor de $p$} & \multicolumn{2}{|c|}{0,0002} & \multicolumn{2}{|c|}{0,04} & \multicolumn{2}{|r|}{$v$} & \multicolumn{2}{|c|}{0,002} & \multicolumn{2}{|c|}{0,01} \\
\hline & \multicolumn{2}{|r|}{$80-96$} & \multicolumn{2}{|c|}{$13-18$} & \multicolumn{2}{|c|}{$35-50$} & \multicolumn{2}{|c|}{$80-85$} & \multicolumn{2}{|c|}{$550-650$} \\
\hline
\end{tabular}

\section{Discussão}

O tecido ósseo possui grande potencial regenerativo com condição de restaurar completamente sua estrutura e funções originais, porém em algumas situações os defeitos ósseos não são reparáveis por si só(13). Quando ocorre uma perda óssea substancial, seja de origem cirúrgica ou patológica, torna-se indispensável a utilização de condutas 
clínicas e terapêuticas para correções estética e funcional, como enxertos ou emprego de compostos biominerais implantáveis ${ }^{(9,11)}$.

Os materiais implantáveis e enxertos ósseos podem atuar por meio de três diferentes mecanismos: osteogênese, que se refere ao material orgânico capaz de atuar na formação óssea diretamente a partir dos osteoblastos; osteoindução, em que todo material é capaz de induzir à transformação das células mesenquimais indiferenciadas em osteoblastos ou condroblastos, aumentando, assim, o crescimento ou podendo formar osso onde não é esperado; e osteocondução, que vem a ocorrer quando um material, frequentemente inorgânico, permite aposição óssea sobre osso preexistente, requerendo a presença de osso e células mesenquimais diferenciadas. Um material osteocondutivo sob tecido mole não produzirá neoformação óssea ${ }^{(20)}$. Otólitos apresentam uma composição físico-química e estrutural que os tornam consistentes com biominerais aptos a promover osteocondução( $(2,3,16,17,22)$.

No presente estudo, os defeitos ósseos tratados com otólitos exibiram a neoformação de trabéculas ósseas cujos espaços medulares pareceram mais estreitados que no grupo controle. Deve ser considerado que o estreitamento dos espaços medulares ocorre às expensas da mineralização acelerada do osteoide na porção interna das trabéculas. Assim, uma vez que os otólitos representam verdadeiros reservatórios de minerais(3), esse achado morfológico poderia estar refletindo a maior velocidade de mineralização do osteoide medular secundária a disponibilização de minerais oferecida pelos otólitos.

No entanto, essa teoria deve ser encarada com bastante parcimônia, já que não houve diferença estatisticamente significativa na área média de neoformação óssea entre os grupos. Esses dados sugerem que o uso de otólitos não pareceu aumentar a síntese de matriz osteoide, com consequente aumento do volume ósseo, mas apenas facilitar a mineralização da matriz pré-existente. Esse expediente poderia promover um leve estreitamento dos espaços medulares sem, contudo, alterar significativamente área ou volume ósseo total.

Observou-se, ainda, fibrose periosteal, que provavelmente ocorreu em resposta ao reparo cicatricial que tomou sede nesse tecido após a injúria em ambos os grupos. Contudo, a margem óssea periosteal mostrou-se nitidamente menos regular no grupo controle, em que a visualização de áreas de reabsorção intercaladas por zonas de aposição era indiscutivelmente mais aparente. O grupo experimental, por outro lado, apresentou superfície periosteal regular, com discreta atividade osteoblástica e atividade osteoclástica inconspícua.

A interpretação desses dados requer a compreensão de que a persistência de atividade blástica/clástica relevante, sem sinais flogísticos evidentes, é forte indicativo de elevado turnover ósseo ${ }^{(23)}$. Sugere-se, pois, que o grupo controle, aos 14 dias, ainda demonstrava sinais morfológicos de atividade remodeladora do tecido ósseo periosteal característico das fases tardias do processo de reparação óssea ${ }^{(25)}$. Por outro lado, a evidente regularidade da margem periosteal no grupo experimental é um indício importante de que, nesse grupo, a atividade remodeladora é menos conspícua. Esse achado poderia refletir tão somente o fato de que a presença dos otólitos - e consequentemente a disponibilidade local aumentada de minerais essenciais à mineralização óssea pode ter atuado como um cofator que aceleraria a dinâmica da neoformação óssea.

A dosagem sérica de cálcio é empregada principalmente para avaliar o comportamento do metabolismo do íon $\mathrm{Ca}^{2+}$ nos organismos. Neste estudo, a dosagem sérica do cálcio apresentou-se estatisticamente similar em ambos os grupos e dentro dos parâmetro de normalidade.

Contudo, é importante destacar que o cálcio sérico circula sob duas formas principais: cálcio ionizado (que exerce ação biológica) e cálcio ligado a proteínas e complexado; o primeiro corresponde, em circunstâncias normais, a 52\% do total e o segundo, a $48 \%$. Considerando isso, em uma série de circunstâncias clínicas, entre elas o processo de regeneração óssea, a dosagem de cálcio total isoladamente não pode ser considerada fator determinante para conhecimento da calcemia funcional(24).

Durante a formação óssea, a produção da matriz de colágeno antecede a mineralização, ocasionando aumento na produção de fosfatase alcalina ${ }^{(21)}$; assim, a dosagem sérica dessa enzima pode oferecer subsídios importantes para compreensão do metabolismo ósseo, uma vez que durante o processo de mineralização seus níveis séricos encontram-se elevados, indicando aumento da atividade osteoformativa $^{(24)}$.

Neste estudo, observou-se que ambos os grupos exibiram níveis séricos elevados de fosfatase alcalina, sugerindo que o processo de formação e remodelação óssea ainda estava em atividade no período de sacrifício (14 dias). Inferese que a utilização de otólitos no processo de correção do defeito ósseo induzido não alterou o padrão de deposição da matriz colagênica osteoide na região de reparo, o que pôde ser observado pela ausência de diferença significativa nas áreas de mineralização entre os dois grupos. 
Referente a alterações histológicas nas áreas de reabsorção óssea, observou-se maior frequência de células mononucleares fagocitárias na superfície periosteal dos animais do grupo controle, fato associado ao elevado turnover ósseo no grupo controle aos 14 dias, que poderia estar relacionado com remodelação do tecido ósseo na área de reparo, enquanto no grupo experimental a fase mais ativa de remodelação já teria passado. Entretanto, esse fenômeno ainda não foi comprovado, estudos posteriores são necessários para validar essa teoria, possibilitando confirmar a relação entre a maior disponibilidade de cálcio promovida pelo uso de otólitos e a redução do tempo de remodelação óssea.
A presença do material exógeno poderia ter, de fato, provocado uma resposta imunoinflamatória um pouco mais elevada, mas as alterações evidenciadas não demonstraram presença de células inflamatórias suficientes para caracterizar o retardamento dos fenômenos de osteodeposição no grupo experimental.

A análise global dos resultados do presente estudo indica que, de forma geral, o uso de otólitos teve pouca influência sobre o processo de neoformação óssea. Contudo, foi observada a tendência a melhores resultados no grupo tratado com esse biomineral que no grupo controle, suscitando a necessidade de estudos posteriores com outros modelos animais e maior escala de tempo para averiguar o real papel desse produto natural sobre a dinâmica de reparação óssea.

\section{Referências}

1. BASTOS, C. C. G. Morfologia de otólitos de algumas espécies de perciformes (Teleostei) da costa sudeste-sul do Brasil. São Paulo, 1990.

2. BORELLI, G. et al. Composition of biomineral organic matrices with special emphasis on turbot (Psetta maxima) otolith and endolymph. Calcif Tissue Int, v. 72, n. 6, p. 717-25, 2003.

3. CAMPANA, S. E.; NEILSON, J. D. Microstructure of fish otholiths. Can J Fish Aquat Sci, v. 42, n. 5, p. 1014-32, 1984.

4. DAY, S. M. et al. Bone injury, regeneration, and repair. In: BUCKWALTER, J. A.; EINHORN, T. A.; SIMON, S. R. Orthopaedic basic science. Chicago: AAOS, 2000.

5. ELLIS III, E. ; SINN, D. P. Use of homologous bone in maxillofacial surgery I. Oral Maxilloface Surg, v. 51, n. 11, p. 1181-93, 1993.

6. FIGUEIREDO, A. S. Estudo morfológico comparativo entre implantes de osso bovino desvitalizado, hidroxiapatita porosa de coral, poliurentana de mamona e enxerto ósseo autógeno, em coelhos. Tese (doutorado) Universidade Federal de São Paulo - Escola Paulista de Medicina, São Paulo, 2001.

7. FINKMEIR, C. G. Bone-grafting and bone-graft substitutes. J Bone Joint Surg, v. 84, n. 3, p. 454-65, 2002.

8. GARCIA, I. R. Avaliação experimental de três diferentes tipos de implantes: polímero de mamona, polietileno poroso de alta densidade e arcabouço óssea bovina, no preenchimento de defeitos ósseos maxilares: estudo histológico e histométrico em macacos. Tese (doutorado) - Faculdade de Odontologia da Universidade Estadual Paulista Júlio de Mesquita Filho, São Paulo, 2000.

9. GARCIA, L. C.; CARVALHO, P. S. P.; OLIVEIRA, J. A. G. P. Ação da radiação laser na reparação de feridas de extrato dental infectadas: estudo histológico em dental infectadas. Estudo histológico em ratos. Rev Gaúcha Odont, v. 43, p. 191-4, 1995.
10. GRANT, C. C. et al. Risk factors for iron deficiency in a hospitalized urban New Zealand population. J Paediatr Child Health, v. 39, n. 2, p. 100-6, 2002.

11. KALISH, B. P. et al. Influence of matrix-suspended demineralized bone on osseous repair using a criticalsized defect in the rat (Rattus norvegicus) calvarium. J Oral Implantol, v. 34, n. 2, p. 83-9, 2008.

12. LEONEL, F. C. E. et al. The action of the castor bean polymer during the bone neoformation. Acta Cir Bras, v. 19, n. 4, p. 342-50, 2004.

13. LINDHEN, J. et al. Tratado de periodontia clínica e implantologia oral. Rio de Janeiro: Guanabara Koogan, 1999.

14. LOWENSTAM, H. A.; WEINER, S. Minerals and macromolecules: on biomineralization. New York: Oxford University Press, 1989.

15. MANN, S. The study of biominerals by high resolution transmission electron microscopy. Scan Electron Microsc, v. 2, p. 393-413, 1986.

16. MURAYAMA, E. et al. Fish otolith contains a unique structural protein, otolin-1. Eur J Biochem, v. 269, n. 2, p. 688-96, 2002.

17. MURAYAMA, E.; YTAKAGI, Y.; NAGASAWA, H. Immunohistochemical localization of two otolith matrix proteins in the otolith and inner ear of the rainbow trout, Oncorhynchus mykiss: comparative aspects between the adult inner ear and embryonic otocysts. Histochem, v. 121, n. 2, p. 155-66, 2004.

18. REDDI, A. H. Morphogenesis and tissue engeneering of bone and cartilage: inductive signals, stem cells and biomimetic biomaterials. Tissue Engeneering, v. 6 , n. 4, p. 351-9, 2000.

19. RIBEIRO, M. S.; SILVA, F.; ARAÚJO, C. E. et al. Effect of low-intensity polarized visible laser radiation on skin burns: a light microscopy study. J Chin Laser Med Surg, v. 22 , p. $59-66,2004$ 
20. SERVICE, R. F. Tissue engineers build new bone. Science, V. 289 , p. 1498-500, 2000.

21. STEIN, G. S.; LIAN, J. B. Molecular mechanisms mediating proliferation/differentiation interrelationships during progressive development of the osteoblast phenotype. Endocrin Rev, v. 14, p. 424-42, 1993.

22. TOHSE, H.; TAKAGI, Y.; NAGASAWA, H. Identification of a novel matrix protein contained in a protein aggregate associated with collagen in fish otoliths. FEBS J, v. 275, n. 10, p. 2512-23, 2008.
23. VIEIRA, J. G. H. Considerações sobre os marcadores bioquímicos do metabolismo ósseo e sua utilidade prática. Arq Bras Endocrinol Metab, v. 43, n. 6, p. 415-22, 1999.

24. VIEIRA, J. G. H. Diagnóstico laboratorial e monitoramento das doenças osteometabólicas. J Bras Patol Med Lab, v. 43, n. 2, p. 75-82, 2007.

25. WISHART, J. M. et al. Effect of age on bone density and bone turnover in men. Clin Endocrinol (Oxf), v. 42, p. 141-6, 1995. 